\title{
A comprehensive review of HIV/STI prevention and sexual and reproductive health services among sex Workers in Conflict-Affected Settings: call for an evidence- and rights-based approach in the humanitarian response
}

\author{
Alyssa Ferguson ${ }^{1}$, Kate Shannon ${ }^{1,2}$, Jennifer Butler ${ }^{3}$ and Shira M. Goldenberg ${ }^{1,4,5^{*}}$
}

\begin{abstract}
Background: While the conditions in emergency humanitarian and conflict-affected settings often result in significant sex work economies, there is limited information on the social and structural conditions of sex work in these settings, and the impacts on HIV/STI prevention and access to sexual and reproductive health (SRH) services for sex workers. Our objective was to comprehensively review existing evidence on HIV/STI prevention and access to SRH services for sex workers in conflict-affected settings globally.

Methods: We conducted a comprehensive review of all peer review (both epidemiological and qualitative) and grey literature published in the last 15 years (2000-2015), focusing on 1) HIV/STI vulnerability or prevention, and/or 2) access to SRH services for sex workers in conflict-affected settings. Five databases were searched, using combinations of sex work, conflict/mobility, HIV/STI, and SRH service terms. Relevant peer-reviewed and grey literature were also hand-searched, and key papers were cross-referenced for additional material.

Results: Five hundred fifty one records were screened and 416 records reviewed. Of 33 records describing HIV/STI prevention and/or access to SRH services among sex workers in conflict-affected settings, 24 were from sub-Saharan Africa; 18 studies described the results of primary research (13 quantitative, 3 qualitative, 2 mixed-methods) and 15 were non-primary research (e.g., commentaries, policy reports, programmatic manuals). Available evidence indicated that within conflict-affected settings, SWs' capacity to engage in HIV/ STI prevention and access SRH services is severely undermined by social and structural determinants including widespread violence and human rights violations, the collapse of livelihoods and traditional social structures, high levels of displacement, and difficulties accessing already scant health services due to stigma, discrimination and criminalization.

(Continued on next page)
\end{abstract}

\footnotetext{
* Correspondence: gshi@cfenet.ubc.ca

${ }^{1}$ Gender and Sexual Health Initiative, British Columbia Centre for Excellence

in HIV/AIDS, St. Paul's Hospital, 608-1081 Burrard Street, Vancouver, BC V6Z

1Y6, Canada

${ }^{4}$ Faculty of Health Sciences, Simon Fraser University, Blusson Hall, 8888

University Drive, Burnaby V5A 156, Canada

Full list of author information is available at the end of the article
} 


\begin{abstract}
(Continued from previous page)
Discussion/Conclusions: This review identified significant gaps in HIV/STI and SRH research, policy, and programming for conflict-affected sex workers, highlighting a critical gap in the humanitarian response. Sex worker-informed policies and interventions to promote HIV/STI prevention and access to HIV and SRH services using a rights-based approach are recommended, and further research on the degree to which conflictaffected sex workers are accessing HIV/STI and SRH services is recommended.

A paradigm shift from the behavioural and biomedical approach to a human rights-based approach to HIV/ STI prevention and SRH is strongly recommended.
\end{abstract}

Keywords: Sex work, Conflict, Post-conflict, Sexual and reproductive health, HIV/Aids, STIs

\section{Background}

Forty armed conflicts were active in 2014, an $18 \%$ increase when compared to the 34 reported in 2013, with many additional countries currently considered fragile states, or involved in post-conflict rehabilitation [1]. Armed conflicts have resulted in unprecedented waves of population displacement as well as other deleterious human rights, public health, and social impacts, including the disruption of traditional social structures, a breakdown in security, and weakened or collapsed health systems [2-5].

Roughly $50 \%$ of the estimated 43 million people made refugees or displaced by conflict are women [6]. While the relationship between conflict and HIV/STI prevalence in the general population is greatly shaped by contextual factors $[7,8]$, and has been found to vary by setting, women have been shown to often be disproportionately vulnerable to the negative health and social consequences of displacement $[9,10]$. The economic, social and political instability of conflict and post-conflict environments, including social and physical displacement, loss of traditional economic options, cultural upheaval, family separation and increased women-headed households, often result in conditions that facilitate significant engagement in sex work as a source of income, particularly for women. Further, armed conflict and the highly policed and militarized environment characteristic of post conflict have been linked to widespread genderbased violence (including rape as a weapon of war; forced abductions), rights violations of women [3, 11-17], and reduced access to, or the interruption of, HIV and sexual and reproductive health (SRH) programmes [4, 18-21]. For example, previous research has shown that within conflict settings, the interruption of condom distribution, disruption of HIV diagnostic services, and shortages of HIV antiretroviral therapy (ART) may drastically impede diagnosis and care [18]. Together, these dimensions of conflict create a complex and challenging situation for prevention of HIV/STIs and delivery of care to conflictaffected populations [10], yet the lived experiences of sex workers, conditions within post-conflict environments, and barriers to accessing HIV and SRH services have largely been unaddressed in research and policy. Furthermore, that programmers and development partners in humanitarian settings may be uninterested in sex work or may conflate issues of sexual exploitation with sex work for ideological or political reasons, creates perverse barriers in the protection of human rights for this group.

Sex workers are a key population disproportionately affected by HIV/STIs [22]. While the majority of sex workers globally are women, there are sizable populations of men and transgender sex workers in many settings [23-25]. HIV/STI prevalence among sex workers varies both across and within regions due to structural factors related to the social, political, economic, legal, and cultural conditions in which sex workers operate, in conjunction with local HIV and STI epidemics $[9,22,26]$. Despite this, research and programmes in the past decade have largely focused on behavioural and biomedical interventions among SWs, which alone, have had only modest effects on the reduction of HIV at the population-level $[22,27]$. A recent global review identified a critical need for further studies examining structural HIV/STI risks or access to care for sex workers in the highest-HIV burden countries [9], to inform the design, adaptation and implementation of effective HIV/STI programmes, particularly needed within conflict-affected settings of sub-Saharan Africa. While sex workers are often highly marginalized even in non-conflict settings, in conflict-affected environments they may face elevated social and structural risks and barriers to care, including abuses of human rights by military and police, gender-based inequities, widespread violence, discrimination and stigma, social and physical isolation, breakdowns in health service delivery systems, and other structural risks that often accompany or follow a crisis $[11,14,26,28,29]$. Despite this, little is known about conflict-affected sex workers' vulnerability to HIV/ STIs or access to HIV and SRH services, or their social and structural drivers within conflict-affected settings. Given the paucity of existing data regarding HIV/STI risks and access to HIV and SRH services within the context of sex work in conflict-affected settings, this comprehensive review aimed to broadly explore and synthesize current evidence on HIV/STI risk, access to HIV and SRH 
services, and their social and structural determinants within the context of sex work in conflict-affected settings (i.e., conflict and post-conflict conditions).

\section{Methods}

\section{Search strategy}

From May to July 2015, we comprehensively searched the peer-reviewed and grey literature for material describing HIV/STI risk or prevention and/or access to HIV or SRH services for sex workers in conflict-affected settings in the last ten years. Five databases (PubMed, Global Health, PAIS International, Social Sciences Citation Index, and Web of Science Core Collection) were searched using combinations of terms related to sex work, conflict, HIV/STI risk or prevention, and HIV and SRH services access related terms (Table 1). Relevant journals and organizational websites were hand-searched, and key papers were cross-referenced. Due to the limited number of relevant peer-reviewed studies available, grey literature (e.g., governmental and non-governmental reports) was searched. Studies conducted with populations of relevance other than sex workers (e.g., Internally Displaced Persons (IDPs), clients of sex workers) were also considered and included where they provided useful context and insight regarding sex work and HIV, STI, or SRH issues in conflict-affected settings. The first and second rounds of screening involved reviewing titles and abstracts, respectively, to identify potentially relevant studies. The third-level of screening consisted of a full-review of remaining records to ascertain relevance in relation to the inclusion criteria. We used the PRISMA guidelines as a reference (Fig. 1).

Table 1 Search terms

\begin{tabular}{ll}
\hline Sex work & "sex work*" OR "prostitute*" \\
& OR "transactional sex" OR \\
& "commercial sex" OR "sex trade" or "FSW*" \\
Conflict environment & "conflict" OR "emergenc*" OR "IDP" OR \\
& "displaced" OR "displaced person*" OR \\
& "displaced people" OR "refugee*" OR \\
& "humanitarian" OR "war" \\
HIV/STI risk or prevention, & "HIV" OR "human immunodeficiency \\
and HIV and SRH services & virus" OR "HIV infections" OR "AIDS" OR \\
& "acquired immunodeficiency syndrome" \\
& OR "acquired immune deficiency \\
& syndrome" OR "sexually transmitted \\
& infections" OR "STIs" OR "Sexual health \\
& services" OR "sexual health" OR \\
& "reproductive health" OR "testing" OR \\
& "test" OR "treatment" OR "ART" OR "ARVs" \\
& OR "sex education" OR "sexual health \\
& education" OR "safer sex" OR \\
& "contraceptives" OR "birth control" OR \\
"family planning" OR "pap smear" OR \\
"condoms" OR "health services" OR \\
"health care" or "healthcare"
\end{tabular}

\section{Inclusion criteria}

Eligible records included peer-review publications (qualitative, quantitative, or review articles) or grey literature (e.g., policy documents, community reports, commentaries, issue reports and briefs, position reports, practical guides for staff working in conflict/post-conflict environments) that met the following criteria: 1) English literature; 2) published from January 2000-July 2015; 3) discussed sex workers (or their clients) working within conflict or post-conflict settings (e.g., refugee or internally displaced sex workers); and 4) included data on HIV/STI risk, prevention, or HIV and SRH services for sex workers in conflict-affected settings. Other reviews were included, as they synthesized key insights in a domain with a paucity of empirical studies. For the purpose of this review, the United Nations definition of sex work was adopted, defined as the sale or exchange of sex for accommodation, protection, food, gifts and other items or services. Studies which were explicitly and solely focused on transactional sex (i.e., broader populations of those who exchange sex for favours or gifts, or who do not necessarily self-identify as sex workers) were excluded. Studies of the trafficking in human beings for the purposes of sexual exploitation were also excluded, unless they included the experiences of sex workers. Conflict-affected sex workers included those who identified as refugees or IDPs from conflict or post-conflict settings (defined as $\leq 10$ years post-conflict) as well as sex workers currently operating in conflict-affected (i.e., current or post-conflict) settings.

\section{Data extraction and analysis}

Endnote was used to manage retrieved items. A Microsoft Excel database was developed to organize and chart study characteristics (authors, year, country, design, population, sample size), key findings, and the following data, where applicable: HIV/STI prevalence, conflict-related variables, qualitative findings, and key programme and policy recommendations. We began by grouping the findings of the epidemiologic studies according to common topics and structural determinants, comparing them across studies. Next, we elicited common themes from the qualitative data and compared these across settings. Lastly, we analyzed existing refugee and sex worker HIV/STI prevention and SRH programme and policy recommendations in conflict settings, seeking to draw lessons and exemplars for future programmes and interventions.

\section{Results}

Five hundred and fifty-one titles and abstracts were screened by the first author to determine eligibility. Four hundred and sixteen eligible records were reviewed. Of the 33 records which met the criteria to be included in this review, the majority $(n=22)$ described conflict or 


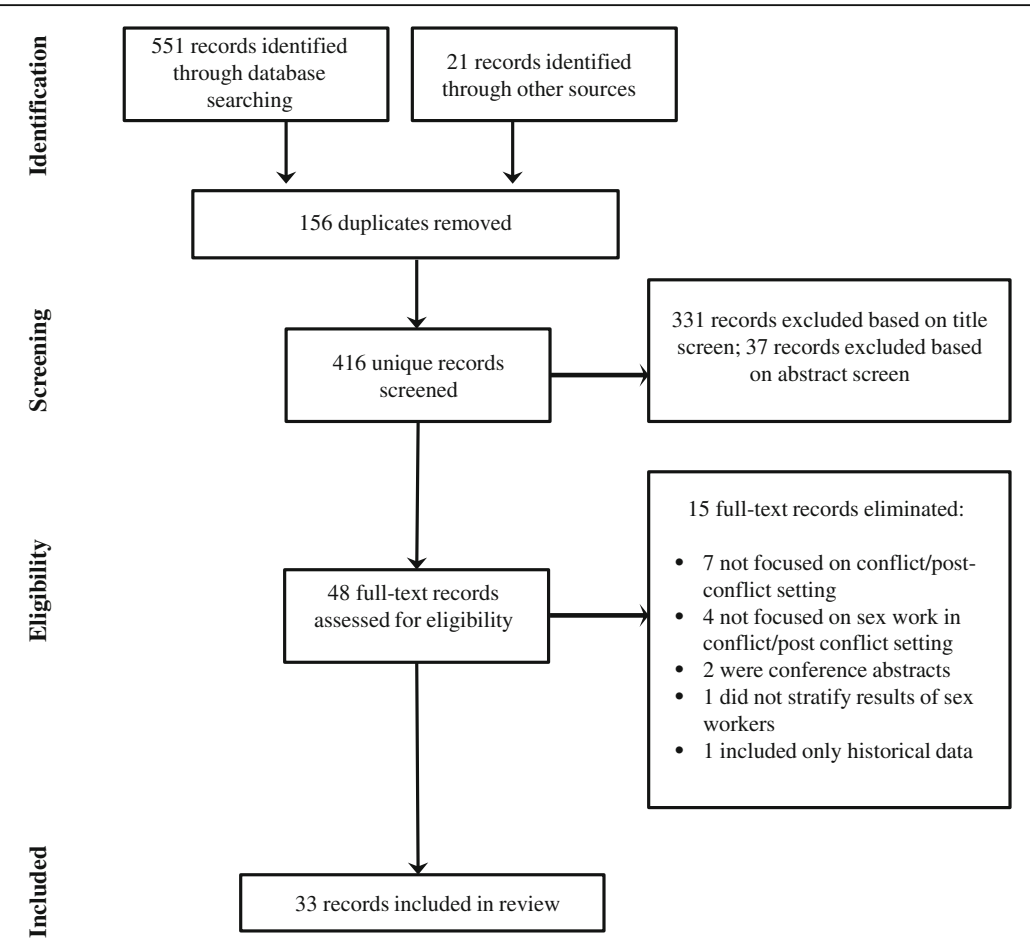

Fig. 1 PRISMA

post-conflict environments in sub-Saharan Africa, 4 were from other settings (e.g., Afghanistan, Bangladesh/ Myanmar, Sri Lanka, and Nepal), and 7 were globally focused. Eighteen studies described the results of peerreviewed primary research articles (13 quantitative, 3 qualitative, 2 mixed methods) (Table 2), and 15 were non-empirical research (e.g., review articles, commentaries, issue reports and briefs, position reports, and practical guides for staff working in conflict/post-conflict environments). A summary of practical guides for staff working in conflict/post-conflict environments $(n=5)$ are described in Table 3. Twenty four of the 33 records were peer-reviewed, while 9 were classified as grey literature/non-peer reviewed. Of the 33 included studies, 14 focused primarily on sex workers in conflict/post-conflict settings, while others discussed broader dynamics of sex work (e.g., sex purchasing) among the general conflict-affected population ( $n=17)$, sex workers' clients (e.g., migrants, combatants) $(n=5)$, or a combination of these groups. While eligibility was inclusive of all gender and sexual orientations, the majority of studies reported on cis-gender female sex workers. One study reported on sexual and gender minority sex workers in displacement and post-conflict settings [23].

Sex work context and links to HIV/STI prevention and risk in conflict-affected settings

Sex workers in conflict and post-conflict settings were found to face an extraordinarily high HIV and STI burden. The burden of HIV among sex workers in studies reviewed ranged considerably, with prevalence rates of $70 \%$ reported among Nepalese sex workers returning from India [30], and $22.3 \%$ among conflict-affected sex workers in Gulu, northern Uganda [31]. STI prevalence also ranged considerably, with an acute self-reported STI prevalence of $40.3 \%$ in Gulu, Uganda [31], and 17\% of sex workers in northern Ethiopia self-reporting history of an STI [32]. Gonorrhea was the most common STI reported in this study, accounting for $45.8 \%$ of the total [32].

\section{Gendered economic impacts of conflict and sex work entry} Available data indicated high rates of sex work in conflict and post-conflict settings globally [11, 30, 33]. A study in Nepal revealed that roughly $19.0 \%$ of sex workers reported having entered sex work directly because of subsistence needs attributed to local conflict [30]. Our review of both the qualitative and the quantitative literature pointed to the ways in which poverty, diminished employment opportunities, difficulty meeting subsistence needs, and challenges to sustainable livelihoods in contexts of displacement influenced engagement in sex work within conflict-affected settings $[3,5,11,17,23,30,32-41]$.

Within the context of family separation resulting from armed conflict, increases in female-headed households were common, and women often experienced reduced access to traditional economic livelihoods, particularly in the absence of male support [36, 37]. Stemming from 


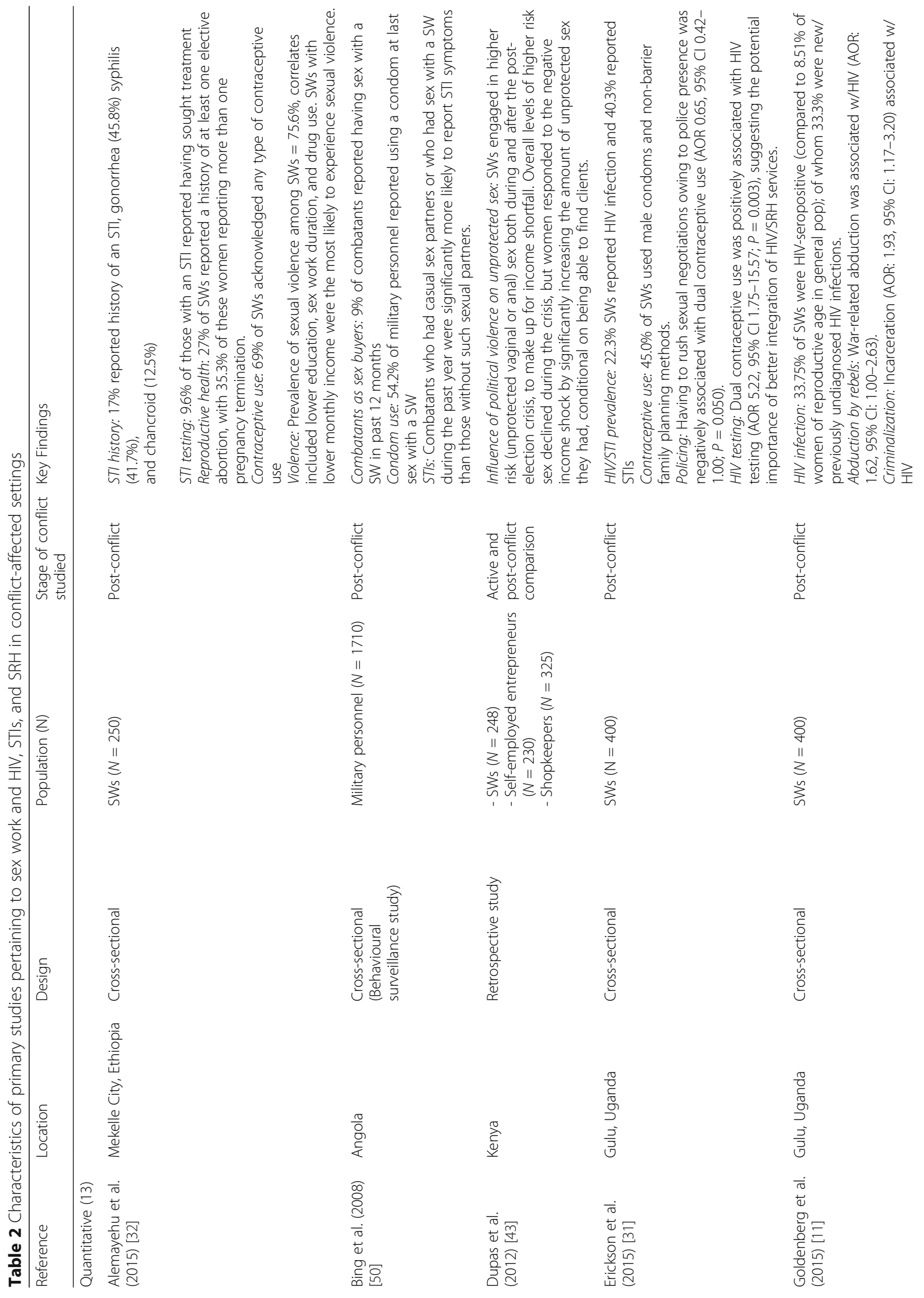




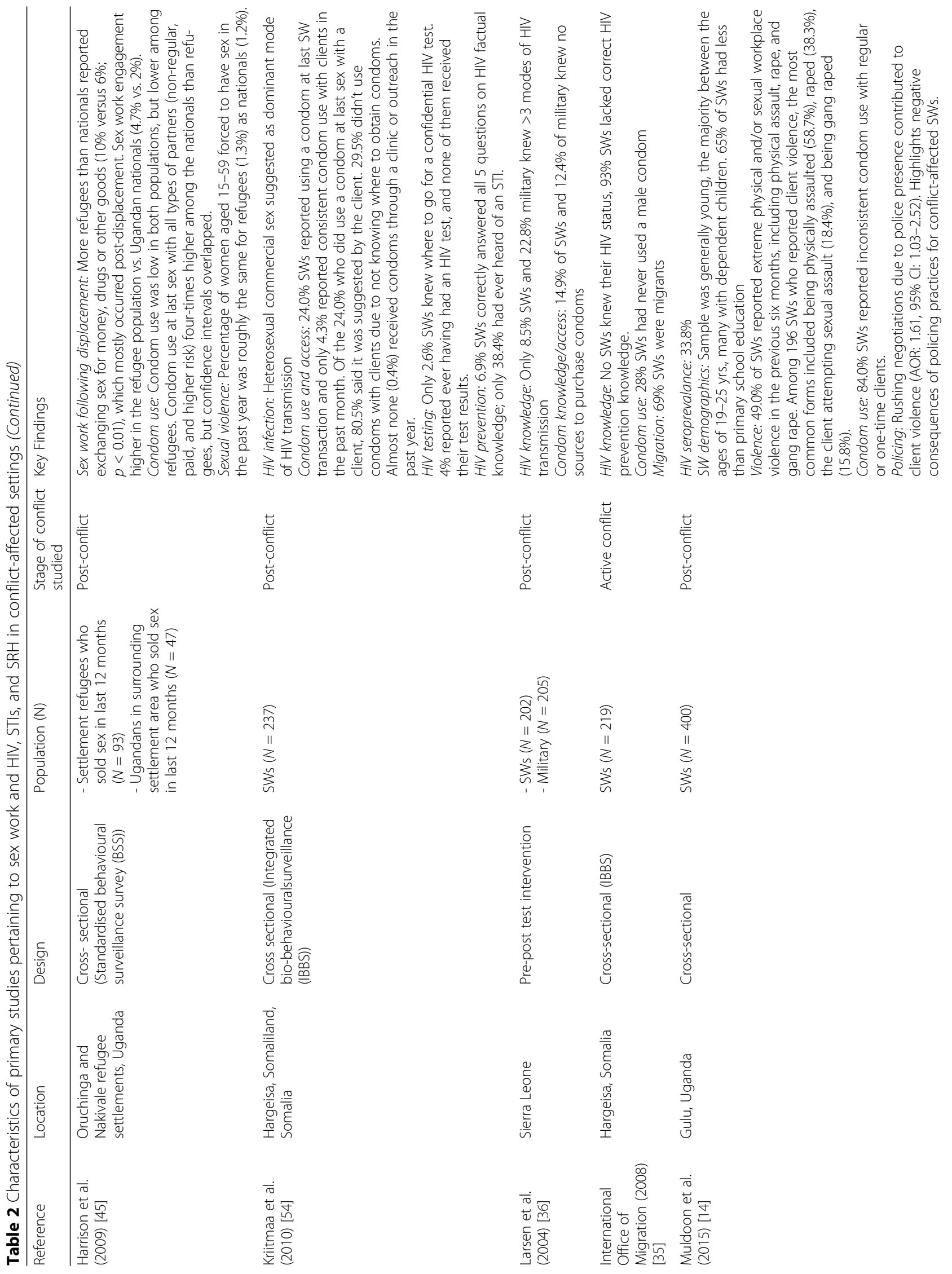




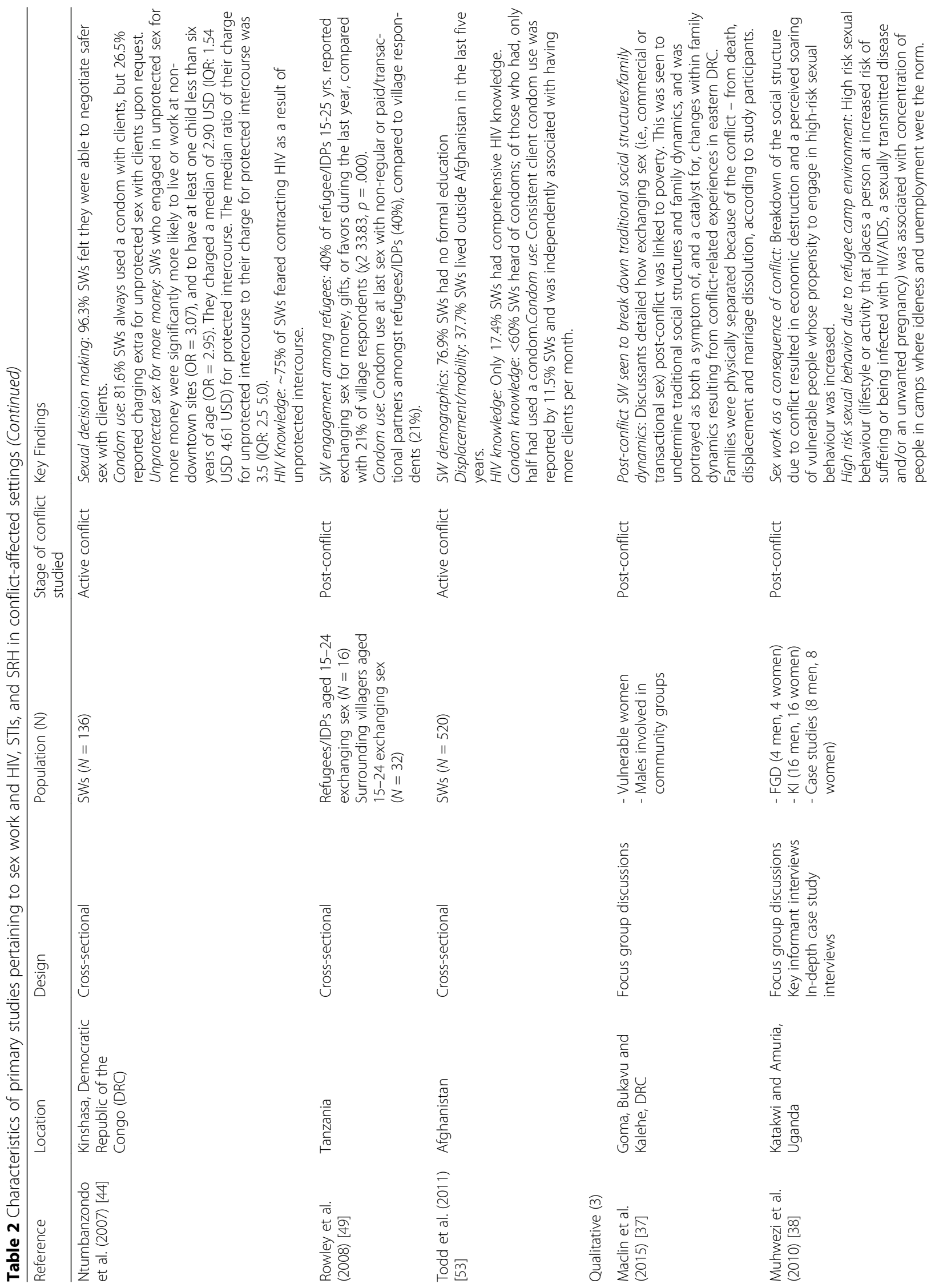




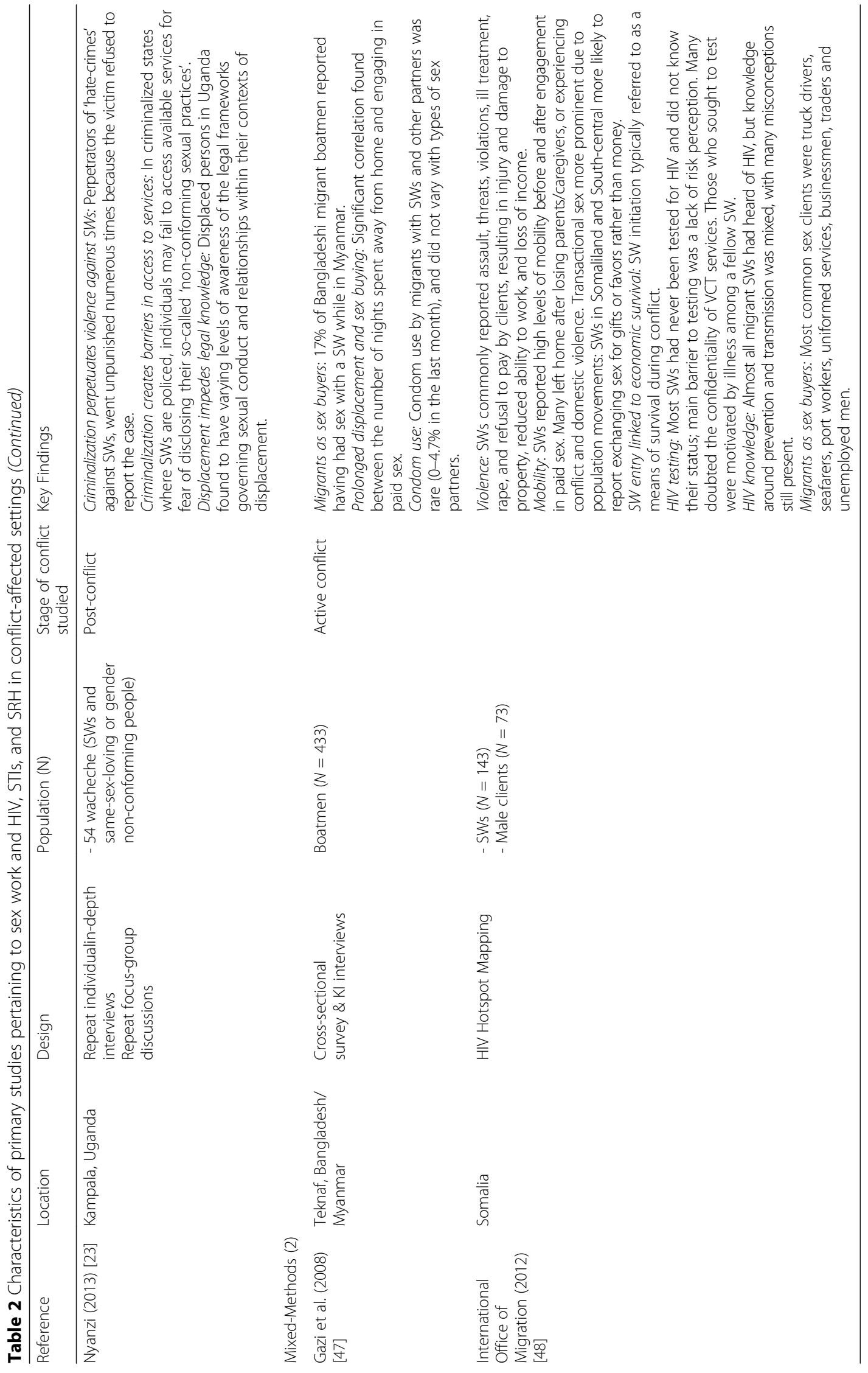


Table 3 Summary of evidence on HIV/STI and SRH policies and programmes for conflict-affected sex workers

\begin{tabular}{lll}
\hline Reference & Document title & Population \\
\hline Inter-Agency Working Group & Inter-agency Field & Refugee/IDPs \\
(IAWG) on Reproductive & Manual on & \\
Health in Crises [55] & Reproductive & \\
& Health in Humanitarian \\
& Settings
\end{tabular}
Key programmes, policies and/or recommendations Sex worker sensitive HIV VCT programmes: Behaviours that put people at a higher risk of exposure to HIV, such as sex work or injecting drug use, also make people more susceptible to coercion, discrimination, violence, abandonment, incarceration or other negative consequences upon disclosure of an HIV-positive test. Healthcare providers require special training and supervision to uphold standards of informed consent and confidentiality for these populations. HIV VCT for these groups should be accompanied by the implementation of a supportive social, policy and legal framework.

Condom availability/distribution: Consult with local staff about how condoms can be made available in a culturally sensitive way, particularly for most at-risk groups, such as SWs and their clients, MSM, IDUs and young people. Ensure the consistent availability of quality male and female condoms. To see an effective reduction of HIV transmission through SW requires $>90 \%$ compliance of correct use of condoms among SWs and their non-regular sex partners. Spermicides: Not recommended for SWs, as they increase risk of HIV

SW specific services: Recommended at health service level, RH officers recommended to hot-spot areas where SWs congregate to target interventions and services STI screening: Service providers recommended to offer regular screening to people with frequent exposure to STIS, such as SWs

STI treatment: Presumptive treatment of SWs recommended at first visit followed by regular visits for speculum/bimanual examination and Gram stain of cervical smear. Right to equality and non-discrimination: Protected by providing access to STI services for the entire population, including adolescents, SWs and MSM regardless of the legal status of prostitution and homosexuality in a country Inclusion of SWs in programming: Involve vulnerable groups encouraged to be involved from the start in programme design implementation and monitoring.

Violence reduction strategies: Should be integrated in SW settings. Programmes recommended working with law enforcement to ensure SW's ability to protect themselves and to ensure safer sex practices by their clients.

SW and child protection: Communities and SWs should be engaged in child protection policies and regulations.

Offer exit-strategies: Programmers encouraged to link SWs and their families to support mechanisms, including the provision of

assistance and incentives for women to leave sex work through a range of legal, economic and social services. Address sex buyers: Work to change the behaviour of SWs' clients (humanitarian staff, peacekeepers, police, general population)

HIV prevention for vulnerable groups: Involve groups from the start in programme design, implementation and monitoring; locate

programme activities in places frequented by the group (clubs, neighbourhoods, etc.); create safe virtual (telephone hotlines) or

physical (drop-in centres) spaces tailored to the group; train health and social workers to provide high-quality, client-friendly, HIV-related services; address structural 
Table 3 Summary of evidence on HIV/STI and SRH policies and programmes for conflict-affected sex workers (Continued)

\begin{tabular}{lll}
\hline Reference & Document title & Population \\
\hline & & \\
& \\
UNAIDS Inter-Agency Task & HIV/AIDS, Gender and & Refugee/IDPS \\
Team on Gender and & Conflict Situations &
\end{tabular}

HIV/AIDS (2001) [16]

Conflict Situations

UNHCR (2010) [67]
HIV and sex work in refugee situations: A practical guide to launching interventions an issue affecting women, men, girls, boys and communities
Conflict-affected SWs
Key programmes, policies and/or recommendations

barriers, including policies, legislation and customary practices, that discriminate against the group and prevent access and utilization of appropriate HIV prevention, treatment and care services.

HIV/STI programmes: National governments, national and international NGOs and UN agencies encouraged to incorporate STI and HIV prevention measures into all humanitarian assistance. Donors strongly encouraged to support these interventions.

Conflict, displacement, HIV and gender inequality research: Assessments encouraged to be carried out, in collaboration between government and agencies, to determine the links these factors in each humanitarian situation. Steps encouraged to be taken to ensure that all humanitarian programmes are responsive to issues documented in these assessments.

Focus on women: All HIV/AIDS programmes and funding in conflict situations encouraged to address the disproportionate disease burden carried by women. Effective approaches include sensitisation, training and behaviour change communication programmes targeting men and boys as well as women and girls. International guidelines for peacekeepers: Steps encouraged to be taken to ensure the implementation of internationally agreed guidelines for the prevention of HIV transmission during peacekeeping operations. Peacekeepers encouraged to receive training on women's rights and gender-based violence as well as HIV prevention. Because peacekeepers have sometimes been implicated in abuses against women and girls, mechanisms of accountability encouraged to also be included.

Sexual violence programming: Programmes encouraged to be designed to support the victims of sexual violence through medical care, counselling, support groups and related activities. Health service packages for girls and women who have been raped encouraged to include post-exposure HIV prophylaxis.

Military HIV/STI programming: Programmes encouraged to be undertaken to improve HIV/STI awareness and treatment within the regular military and rebel forces, where these are systematically demobilised. This will have important impacts on sexual health risks to civilians from ex-combatants. Civilians, including SWs near military installations, encouraged be included in these awareness raising and treatment programmes.

This guide is intended to assist those working to slow transmission of HIV and other STIs in humanitarian settings. The focus is on intervening where HIV has the potential to spread quickly - with SWs and their clients. Practical, step-by step activities are recommended for addressing HIV in sex work within refugee situations, including:

1. Sensitization and buy-in: Engage agencies responsible for refugees, community groups, and leaders.

2. Identification, hotspot mapping and snowballing: Collect baseline and risk information, provide condoms, and assess need through snowball sampling, mapping hotpots, and estimating numbers of SWs and clients. 3. Protection: Support registration, ensure safe access to basic needs, and reinforce GBV prevention and child protection activities

4. Profiling and case management: Gain deeper understanding of sex work in the community, identify those most at vulnerable/risk, and develop case management plans to address urgent problems 
Table 3 Summary of evidence on HIV/STI and SRH policies and programmes for conflict-affected sex workers (Continued)

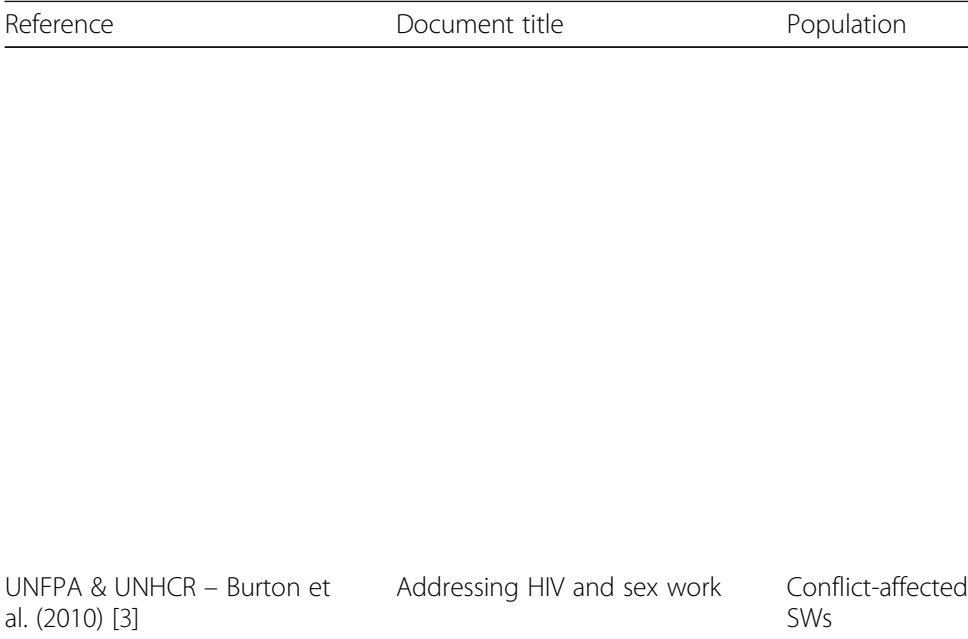

al. (2010) [3]

Inter-Agency Task Team on HIV and Young People (n.d) [12]
HIV Interventions for Young People in Humanitarian Emergencies
Conflict-affected youth
Key programmes, policies and/or recommendations

5. Forming Multi-Functional teams (MFTs): Guide programme implementation, identify roles and responsibilities, strengthen partnerships, and ensure coordination and monitor progress

6. Building peer-led systems with SWs: Meet and review programme objectives, introduce verbal contract about participation in peer group, ask SWs to choose their leaders and agree to meet regularly, provide peer leaders with training, condom education, promotion and distribution kits

7. Health services: Assess services looking at HIV/STIrelated areas, advocate and ensure SWs have access to non-judgmental services

8. Male and venue-based interventions: Engage men and boys, and offer simple venue-based interventions 9. Monitoring

Interventions to respond to HIV and sex work in humanitarian settings are both necessary and feasible, even during an emergency. In situations where comprehensive HIV programmes have already been established but where SWs have not yet been reached, a basic set of sustainable multisectoral activities can be established within six months.

Key Activities per phase include:

Preparedness

1. Integrate HIV and sex work into contingency planning: Identify existing SW networks and programmes, map services, and develop contingency plans for rapid restoration if disrupted

Emergency phase

2. Expedite registration, risk identification and protection: Identify those most at risk, ensure protection, establish GBV services, and promote codes of conduct

3. Ensure safe shelter and access to food and basic necessities

4. Provide basic SRH and HIV services: Implement MISP, establish basic STI/SRH services and outpatient clinics, and implement basic HIV services

5. Start outreach: Begin mapping and engagement with SWs, identify sex-work venues, and distribute condoms and information

Stabilised phase

6. Build supportive environments and partnerships: Establish peer groups, support SW-led approaches, strengthen existing women's groups to reach non selfidentified SWs, conduct rapid assessments, and plan interventions

7. Reinforce protection: Strengthen prevention of GBV and sexual exploitation, and find ways to involve men 8. Expand to comprehensive HIV and SRH services including STI services

9. Expand targeted services: Support transition of peer activities to broader community mobilisation, strengthen venue-based and special clinics for identified SWs, and work with clients to reduce demand for unprotected paid sex

10. Provide social/economic/legal services: Strengthen legal protections and establish self-regulatory boards, increase livelihood and educational opportunities for the most vulnerable, and prepare for appropriate durable solutions

Provision of basic health care and support: Providing basic health care and support to younger, most-at-risk groups, such as people who inject drugs (PWID), SWs and MSM. Special attention is needed to address the needs of younger age groups, particularly during the minimum response stage. 
unequal gender norms and limited economic opportunities for women, existing evidence highlighted how women were particularly likely to exchange sex for money, accommodation, or other goods (e.g., food, clothing, healthcare, favours, gifts, access to education for their children, protection), and even passage across a border [3, 23, 33, 36, 41]. The following testimonial from a Somalian sex worker highlighted how the unequal gendered socio-economic impact of conflict influenced her choice to engage in sex work:

"[The first time I sold sex] I was 12 years old ... my father and mother had died ... I didn't have anyone to take care of me, and [didn't] have anything to eat or dress in. Being a sex worker was the only choice." (Somalian sex worker aged 25 [35].

Inconsistent condom use within conflict-affected settings was commonly elucidated as a consequence of reduced negotiating power due to financial constraints during times of social unrest [30, 36, 39, 40]. Conflictaffected sex workers in sub-Saharan Africa commonly supported dependent children [14, 42], and having children (especially young children) was associated with increased HIV risks including engaging in unprotected sex for more money [14]. Although further research is needed in this area, two studies suggested increased need/opportunity to charge extra money for unprotected intercourse during or following a crisis [43, 44], including a study of Kenya's 2008 post-election violence on sex workers and their clients, where dramatic declines in income, expenditures, and consumption in the general population resulted in more unprotected sex [43]. These findings elucidate potentially important effects of active vs. post-conflict settings on the sex industry, where conflict environments with a large presence of military/ peacekeeping personnel as potential clients may increase demand for sexual services, (while reducing sex workers' control to safely negotiate condom use with clients), whereas smaller social and economic crises (represented by dramatic declines in income) may result in more sex workers willingly offering unprotected sex to make up for income shortfalls. Authors further highlight the increased risk for sex workers during times of political and economic crisis, where financial gains of unprotected sex may outweigh the known risk of HIV/STI acquisition. Although sex workers in non-conflict settings also often report economic pressures for unprotected sex for higher pay, our review suggested that these pressures may be amplified within conflict-affected settings.

\section{Displacement and mobility}

Displacement and high mobility were common experiences reported by conflict-affected sex workers
[11, 35, 45, 46], and clients of sex workers [35, 41, 45, 47], across diverse geographical and socio-political contexts. Within the studies reviewed, displacement and mobility were consistently associated with increased engagement in sex work $[35,41,45,48,49]$, particularly in the postconflict stage [35, 45, 48, 49]. While military/peacekeepers commonly purchase sex in conflict-affected environments $[2,16,34,38,41]$ displacement may increase demand for sex work from other clients particularly during the rehabilitation stages of a conflict, due to men travelling greater distances for employment, and spending greater amounts of time separated from family [37]. Further, in sub-Saharan Africa, the geographical areas most heavily affected by HIV are often those linked with high longterm mobility, adjacent to main transport routes or in border regions [46].

Findings from numerous contexts, predominantly within sub-Saharan Africa, indicated that women in transit or temporarily displaced due to war or violence were more likely to report having received money or goods for sex than their non-mobile counterparts [26], and this was often linked to enhanced challenges and barriers accessing HIV and SRH services. In a study seeking to understand the relationship between armed conflict and HIV infection among conflict-affected sex workers in Gulu, northern Uganda, 66.5\% of respondents reported living in IDP camps, among whom HIV prevalence was $71.9 \%$ compared to $63.8 \%$ of non-mobile sex workers [11]. In Somalia, mobility of sex workers was further associated with increased HIV/STI risk due to porous borders with countries that have higher HIV prevalences (Djibouti, Ethiopia, Kenya), and the presence of mobile populations associated with other HIV epidemics in the region (e.g., truck drivers and the military) [35].

\section{Presence of military and peacekeepers}

The presence of military and peacekeepers with expendable incomes represent unique aspects of conflict-affected settings which strongly shape the context of sex work and HIV/STI prevention in such contexts $[2,3,5,16,29,33,34,36,38,39,41,50]$. Combatants and peacekeepers stationed far from home were more likely to frequent sex workers during war and migration [5], had higher rates of STIs than the general population [16], and were more likely to engage in higher-risk behaviour while participating in missions than within their home communities [2]. Even during peacetime, STI rates among armed forces are generally $2-5$ times higher than in civilian populations; in times of conflict, the difference can be 50 times higher or more [39]. The circumstances of military service were said to make soldiers both more vulnerable to HIV/STI infection and more likely to transmit such infections - for example, soldiers are typically young, male, sexually active, and separated from their 
normal partners, which has been shown to facilitate sex purchasing [39]. Peacekeepers may also originate from countries with higher HIV prevalence rates than the local community in conflict, potentially exposing sex workers to further risk [36]. In Gulu, northern Uganda, exposure to war and conflict related events, such as abduction by the Ugandan Lord's Resistance Army (LRA), was found to significantly increase the likelihood of HIV seroprevalence in sex workers (AOR: 1.62, 95\% CI: 1.00-2.63) [11].

\section{Violence}

Physical, sexual, and emotional violence against sex workers in conflict-affected settings, by both clients and intimate partners was alarmingly high within studies [11, 14, 31, 32, 35, 37, 38]. Among sex workers in post-conflict northern Uganda, almost $50 \%$ experienced extreme physical and/or sexual workplace violence in the previous six months, including physical assault, rape, and gang rape [14]. Reports of assault, poor treatment, and threats were commonly reported by sex workers in Somalia, as were rape and refusal to pay [35]. An epidemiological study of 250 sex workers in post-conflict Mekelle, northern Ethiopia, demonstrated high rates of violence, with $46-60 \%$ of sex workers reporting rape or forced sex [32]. In Somalia, incidents of violence most often led to physical injuries and damage to property, reducing sex workers' ability to work, creating medical costs, and leading to a loss of income [35], which in turn, may lead to a greater likelihood of engaging in sex for more money. In conflict-affected Gulu, northern Uganda, 74.7\% of sex workers reported that they would experience violence from clients, and $60.8 \%$ from intimate partners, if they asked them to wear a condom [31]. Prolonged exposure to traumatic conflicts was found to be linked to severe mental distress, including persistent feelings of despair, hopelessness, pathological fear, and suicidal inclinations, which may have indirect effects on conflict-affected sex workers' vulnerability to HIV infection, as it not only predisposes women to exploitation or HIV risk, but may also hinder uptake of HIV preventative and treatments services $[16,38]$.

\section{Police/ criminalization of sex work}

In Uganda, Ethiopia, and Sri Lanka, criminalization of sex work led to rushed negotiations with clients due to police presence $[11,29,31]$, which significantly increased the odds of client violence [14], further undermining uptake of HIV/STI and SRH services [31]. Among sex workers working in post-conflict Uganda, over one-third (37.3\%) reported having to rush negotiations with clients as the result of police presence in the last six months [31], and exposure to incarceration (AOR: 1.93, 95\% CI: 1.17-3.20) was found to be positively and independently associated with HIV infection [11]. For refugee sex workers in particular, an arrest for sex work could greatly jeopardize an asylum claim, or result in deportation. As a consequence, the high stakes of getting caught force sex workers to take greater risks with their safety, such as working alone or in secluded areas.

"When I entered the circle of refugees who sell sex, the first thing I learnt was to avoid places the police patrol. When a Ugandan prostitute is arrested, the police have sex with her if she wants to be released without trying. What will happen to me, a refugee?" (31-year-old sex worker from Congo) [23].

Criminalization further propagates an environment in which violence against sex workers is tolerated, resulting in severe vulnerabilities in which sex workers are unable to seek protection from law enforcement authorities [11, 23, 29, 31, 32]. In Uganda, many sex workers revealed that they failed to report human rights violations to police, for fear of re-victimization from public disclosure of their sex work [23]. Numerous instances were documented in which perpetrators of 'hate-crimes' against sex workers went unpunished because the victim refused to report the case. In this way, current legal responses to sex work may inadvertently protect perpetrators of violence, and simultaneously expose sex workers to injustice by curtailing access to mechanisms of legal redress [23].

Displaced persons in Uganda were found to have varying levels of awareness of the legal frameworks governing sexual conduct and relationships within their contexts of displacement [23]. In post-conflict states, criminalization has been revealed to undermine effective HIV and harm reduction programmes, by driving key populations underground, and creating environments in which abuses against sex workers' human rights are tolerated [51, 52]. Further, incarceration may elevate the risk of HIV transmission through a lack of access to condoms, harm reduction supplies, or antiretroviral medicines, as well as through increased vulnerability to human rights violations or sexual assault during detention [52].

\section{Access and uptake of HIV/STI and SRH services}

During acute stages of conflict when food insecurity, sanitation, and related infectious diseases (e.g., cholera) remain pressing priorities, provision of HIV/STI and SRH services may be negatively impacted, both for the general population and for key populations, including sex workers. Unfortunately, our review identified very few studies describing the nature of HIV/STI or SRH services offered or utilized by sex workers within conflict or post-conflict settings. Available evidence generally indicated that conflict-affected populations face unique 
obstacles to accessing HIV/STI information, treatment, condoms, and other SRH services. For example, migrant populations often face substantial barriers to access, including the potential for being turned away by providers on account of their status as foreigners [26]. In addition to these already pervasive barriers, evidence suggests that access to HIV and SRH services in conflict-affected settings may be particularly challenging for sex workers, due to the additional marginalization, discrimination, and stigma sex workers face on the basis of their occupation [3]. In post-conflict Gulu, northern Uganda, and over half $(55.5 \%)$ of sex workers reported experiencing difficulty accessing condoms [11]. In general, HIV, STI and SRH services for conflict-affected sex workers were found to be extremely limited, or where available, lacking in scope, scale-up, and reach (e.g., local-level condom distribution, occasional offers of HIV testing) $[3,11]$.

HIV/STI prevention Limited exposure to HIV/STI prevention information, condom promotion, and low general HIV knowledge among conflict-affected sex workers was found across multiple settings, including Somalia, Uganda, and Afghanistan [31, 35, 48, 53]. In an epidemiological study of 218 female sex workers in Hargeisa, Somalia, 93\% lacked accurate knowledge on HIV/STI prevention, and $28 \%$ had never used a male condom [48]. In a study seeking to asses HIV awareness, knowledge, and condom use among women sex workers in Jalalabad, Kabul, and Mazar-i-Sharif, Afghanistan, fewer than $60 \%$ of the 520 sex workers interviewed had heard of condoms [53]. Of those who had, only half had ever used a male condom [53]. In a study of 400 young women sex workers in post-conflict Gulu, Uganda, $59.25 \%$ reported difficulty accessing condoms or contraceptives, and approximately one-third had never received a condom demonstration [31]. A study conducted by the same group in Gulu Uganda, found that $83.3 \%$ of post-conflict sex workers reported inconsistent condom use in the prior six months, for both one-time and repeat clients [11].

One study investigating patterns of condom use with paying sex partners among refugees/IDPs indicated the potential for increased uptake of HIV/STI prevention services during the acute stage of conflict, compared to the post-conflict rehabilitation stage [49]. In a study comparing refugees in the Lugufu refugee/IDP camp at Tanzania's western border with the DRC to their surrounding host villages, condom use with paying sex partners was quite low (44\%) among 15-24 yr. olds in the camp, but was substantially higher than rates in the surrounding villages (25\%) [49]. As refugee/IDP camps are heavily influenced by UN and international aid organizations, the authors posited this may be due to an influx of external aid and health services (e.g., condoms, sexual health information) in some camps [49]. However, we did not identify any studies specifically comparing condom use or other indicators of HIV/STI prevention access among sex workers themselves across various stages of a conflict (i.e., acute, post-conflict).

HIV/STI testing and treatment Despite high rates of STIs (17.0\%) among sex workers in post-conflict northern Ethiopia, STI treatment was quite low with only 9.6\% of those with history of an STI reporting seeking treatment [32]. In Somalia, the majority of sex workers had never been tested for HIV and were unaware of their status. Low awareness of testing locations and concerns regarding the confidentiality of testing were identified as primary barriers [35, 54]. In Gulu, northern Uganda, 92\% of women sex workers reported having tested for HIV in the past 6 months, while only $43 \%$ reported testing for STIs. This aligns closely with the $40.25 \%$ reporting history of an STI infection in the past 6 months, indicating that while testing for HIV may be practiced preventatively, STI testing appears to be done more symptomatically [31]. Of note, this study also found that HIV testing was more common among women who used dual contraceptives than women who had not [31].

SRH services Despite the likely challenges and unique barriers faced by sex workers seeking to access SRH services within conflict-affected settings, little evidence was identified pertaining to this. Only two studies of sex workers' access and use of other SRH services such as contraception or pregnancy terminations were identified amongst conflict-affected sex workers. An epidemiological study of hormonal contraception use (i.e. birth control pills, Depo-Provera injectables, or implants) among 400 conflict-affected sex workers in Gulu, northern Uganda, found that less than half (49.8\%) reported ever using these contraceptives, $10.3 \%$ had never used condoms for pregnancy prevention, and $45 \%$ reported having ever used dual contraceptives (e.g., birth control pills and condoms at the same time) [31]. In northern Ethiopia, 27\% of sex workers reported a history of at least one elective abortion, with $35.3 \%$ of these women reporting more than one pregnancy termination [32]. In this same study, $69.0 \%$ of sex workers acknowledged history of any type of contraceptive use [32].

\section{Policy and programmatic responses to HIV and SRH in sex work in conflict-affected settings}

Sex work specific recommendations are largely absent from international guidelines regarding HIV/STIs or SRH in conflict and emergency settings, including those of the United Nations High Commissioner for Refugees 
(UNHCR), The Joint United Nations Programme on HIV and AIDS (UNAIDS), United Nations Security Council, and the World Health Organization (WHO). Currently, United Nations agencies (such as UNHCR and UNFPA), bilateral donors, and non-governmental organizations offer policy and programme support for the provision of HIV/STI and SRH services to refugees and IDPs in emergency settings. The Inter-Agency Working Group (IAWG) on Reproductive Health in Crisis, spearheaded by UNHCR and UNFPA, has produced a manual specific to humanitarian settings that serves as a guide to SRH and HIV/STI services beginning with the onset of an emergency, and continuing as the situation stabilizes [55]. The Inter-agency Field Manual on Reproductive Health in Humanitarian Settings incorporates technical standards set by the WHO, and advocates for increased HIV/STI and SRH services for displaced populations as part of broader primary health care activities. It has identified programmatic strategies to facilitate this process, including implementation of the Minimum Initial Service Package (MISP), a set of priority actions in response to the life-saving reproductive health needs of populations at the onset of an emergency. Services included in the MISP for emergency situations include: supplies for infection control, safe deliveries and management of obstetric emergencies, treatment for victims of sexual violence, condoms, oral and injectable contraceptives, drugs for the treatment of STIs, emergency contraception and HIV postexposure prophylaxis for survivors of rape, and manual vacuum aspiration equipment for the treatment of postabortion complications [56]. The manual additionally includes guidance on strategies and priorities that should follow when the situation has stabilizes, including adolescent reproductive health, family planning, maternal and newborn health, comprehensive abortion care, gender-based violence, management of sexually transmitted infections, and HIV. While the need for tailored programming or policy recommendations specific to key populations, such as sex workers are largely absent, a number of chapters (e.g. family planning, STI, HIV) do provide insight on how to address the needs of sex workers most effectively. Examples include suggestions to integrate violence reduction strategies in sex work settings, to consult with local staff about how condoms can be made available to sex workers in a culturally sensitive way, to offer regular STI screening services, to work with law enforcement to ensure sex workers have the ability to protect themselves and to ensure safer sex practices by their clients, and to include them from the start in programme design, implementation and monitoring [55]. An overwhelming challenge to provision of these services which is also elucidated, is the reality that health centres in countries with laws against prostitution or discriminatory practices against people engaged in sex work (i.e., the majority of countries worldwide), do not offer services to sex workers [55].

The Prevention and Treatment of HIV and other Sexually Transmitted Infections for Sex Workers in Low-and Middle-income Countries, the product of a joint consultation between the WHO, UNFPA, UNAIDS, and the Global Network of Sex Worker Projects (NSWP), summarizes best practices for evidence-based HIV/STI programming for the general population of sex workers [57]. Research and consultation with sex work groups and key humanitarian and global health organizations could be useful to assess the extent to which key principles and practices described in this document (e.g., voluntary HIV testing, decriminalization, community engagement) may be applicable to conflict-affected settings, as well as to articulate and develop strategies to address the unique challenges faced by sex workers in these settings.

Initial steps have been taken to more explicitly address HIV/STI and SRH within the context of sex work in some refugee programmes in the East and Horn of Africa, Latin America and parts of Asia [3]. Based on these experiences, and under the overall framework of the UNAIDS Guidance Note on HIV and Sex Work, UNHCR and UNFPA produced a brief Technical Note on HIV and Sex Work in Humanitarian Settings [3]. Its primary objective is to inform humanitarian agencies of steps that can be taken to integrate sex worker-inclusive programming into emergency responses. Its recommendations reflect experience from a number of different settings, and are meant to be adaptable to many different conditions and cultural contexts. The Technical Note highlights three pillars which aim to: [1] assure sex workers' universal access to prevention, treatment, care and support; [2] strengthen partnerships with sex workers through community consultation; and [3] reduce vulnerability and address structural issues. The Technical Note also addresses "key activities per phase," which assign importance of activities for the preparedness, emergency, and stabilized phases of a conflict or humanitarian emergency [3]. While these recommendations offer valuable guidance for staff in the field, it is largely up to programme staff to adopt these strategies, and further development of policy guidance to explicitly protect the distinct needs and rights of sex workers in conflict settings may be needed.

Strong global evidence indicates that community empowerment approaches to HIV programming for sex workers, including specific efforts to carefully involve consultation, leadership, and partnership with sex workers in the design and provision of services, are linked to improvements in service uptake and access $[3,58]$. A growing number of countries that have scaled up sex 
worker-led/inclusive interventions have reported stabilization, and even reversal, of their HIV epidemics [3]. Despite the demonstrated effectiveness of communitybased sex work HIV prevention programmes, few countries have scaled-up such initiatives [59]. In low and middle-income countries, HIV programmes have traditionally followed generalized approaches, with insufficient attention being paid to the individuals and groups at highest risk of acquiring and transmitting HIV/STIs.

In light of evidence that general-population local health services may not be equipped to meet sex workers' needs and circumstances [23], there remains a need for targeted approaches to offering and delivering HIV, STI and SRH services for sex workers in displacement and post-conflict contexts, with a particular need for programming efforts that acknowledge and address the diversity of conflict-affected sex workers, including both cis-gender women and those who identify as gender/sexual minorities.

\section{Discussion}

This review highlighted a paucity of sex worker-focused research and interventions in conflict and post-conflict settings. Most of the studies identified were from postconflict sub-Saharan Africa. Despite our best efforts to identify qualitative or quantitative studies elucidating the specific challenges to health access faced by sex workers during the acute stage of conflict, such studies were largely absent from the peer-reviewed literature, likely due to the substantial practical and ethical challenges involved with collecting such information during complex emergencies. However, available evidence indicated that within conflict-affected settings, sex workers' capacity to engage in HIV/STI prevention and access SRH services can be undermined by social and structural determinants including widespread violence and human rights violations, the collapse of livelihoods and traditional social structures, high levels of displacement, and difficulties accessing already scant health services due to stigma, discrimination and criminalization.

Unprotected sex between male clients and female sex workers was posited as the primary means of HIV acquisition and transmission in a number of conflict-affected countries under study $[30,35,48]$; yet few, if any studies, examined the HIV burden or social and structural conditions that shaped HIV vulnerability or reduced access to SRH services.

Evidence highlighted the association of conflict-related mobility and displacement with increased engagement in sex work, yet failed to explicitly identify the links between displacement/migration and HIV/STI risk or access to care among this group. While some women intentionally migrate for sex work, others engage in sex work to meet subsistence needs during conflict or migration [60]. Given that migration and displacement are associated with increased socio-economic impacts, social isolation, gender inequalities, and stigma and discrimination [60], HIV/STI risks and barriers in access to care are likely to be amplified among vulnerable groups (like sex workers) in conflict and post-conflict environments. For example, social isolation may pose barriers to the development of support networks to mitigate risk among mobile populations. Evidence from Mexico and Central America has suggested that among sex workers, the formation of community networks - an important pillar of HIV prevention in other contexts - is hindered by the constant mobility of sex workers, who "cannot establish trusting relationships with each other or with others [...] [and consequently] cannot demand protected and secure working conditions" [61]. Further research is required which assesses the unique ways in which contexts of mobility and displacement impact HIV/STI risks for sex workers in conflict and postconflict environments.

Sex work is criminalised in 116 countries globally, with 27 countries in sub-Saharan Africa having official legislation criminalising sex work and 'prostitution' [62]. The structures of social stigmatization which criminalisation reinforce inhibit sex workers' ability to protect themselves from violence and health risks including HIV and other STIs [63]. The illegality of sex work has additionally been understood to lend legitimacy to ongoing abuse and humiliation of sex workers [64]. Numerous qualitative studies reveal the alarming scope and nature of human rights abuses committed against sex workers by local military and police officials themselves:

"There was this time when I was arrested by six policemen. They afterwards demanded sex from me. One of them threatened to stab me if I refused. I ended up having sex with all of them and the experience was so painful." (26 yr. old male sex worker, Mombasa, Kenya) [51].

"They were policemen. There's a car park next to the flat and they took me there and they took turns." (26 year old female, Bulawayo, Zimbabwe) [51].

This continues to be a major challenge in many postconflict settings where key populations (e.g., gender/sexual minorities such as MSM) are harshly criminalized. For example, numerous sub-Saharan African nations (e.g., Uganda, Kenya, Zimbabwe) have a history of impeding sex workers human rights (e.g., the right to assembly) [14] and have imposed increasingly harsh and draconian criminal laws targeting key populations. In many cases, the political persecution and stigmatization of key populations can foster the perception that antiretroviral therapy (ART) should not be 'wasted' on sex 
workers, a group most in need of treatment [14, 64, 65]. In states where sex work is policed, individuals may fail to access available services for fear of disclosing their socalled 'non-conforming sexual practices'. A qualitative study of gender/sexual minority refugees engaged in sex work in Uganda highlighted that often alternative sexual cultures (including sex workers, transgender individuals, and men who have sex with men), are silenced and marginalized within current structures of programming, policies and service delivery [23].

In additional studies, sex workers in non-conflict areas have noted the influence broader contexts of criminalization, marginalization, and social exclusion have had on their experiences interacting with the healthcare system.

"We are despised in the hospitals. They [providers] say, 'We don't have time for prostitutes' and they also say that if one prostitute dies then the number reduces." (27 yr. old female sex worker, Kampala, Uganda) [64].

"When I fell sick and went to a health centre and they realised that I was a sex worker, they did not treat me like a human being. When the health worker came to attend to me [...] I was told that he had no time for me. So I left without getting treatment." (19 yr. old female sex worker, Mombasa, Kenya) [64].

"We were in the queue with everyone else when suddenly one of the nurses came out and loudly said 'the sex workers who have come ... please go and queue at the back of this line, we will attend to you last" (29 yr. old female sex worker, Zimbabwe) [65].

We found little information regarding the lived experiences of conflict-affected sex workers as they attempt to access SRH and HIV services in these challenging environments, and about how commonly such access is compromised or even denied outright, information that is greatly needed to optimise the design of services for this at-risk population [64]. Given the widespread acknowledgment of barriers in access to SRH and HIV services for sex workers in non-conflict environments, paired with the pronounced vulnerability conflict and mobility impart on social isolation and stigmatization of this group, this presents a considerable gap within the literature.

Further research focused on social and structural factors such as migration and displacement, sex work environments, economic contexts, political and legal inequities, and human rights abuses suffered by sex workers in conflict-affected settings is recommended. Rigorous studies investigating the specific links between conflict exposure, these socio-structural forces, and health outcomes among conflict-affected women at risk of, or living with HIV, including sex workers, remain urgently needed. Research detailing HIV/STI or SRH services available during conflict, and the challenges, facilitators, or inequities sex workers face in their interactions with these programmes and services is sorely needed. Given the paucity of studies explicitly articulating specific conflict experiences or their links to HIV/ STI risks and programme access among sex workers, further research focused on better understanding the specific impacts of conflict experiences (e.g., war-related human rights violations) are recommended. We see this review as a preliminary step in better understanding these issues, and recommend future research and policy work be focused on evidence-based interventions and the impact of programmatic changes.

Findings from this review suggest an urgent need to scale up access to quality, accessible, and nonstigmatizing SRH and HIV programmes for sex workers in conflict-affected areas. Considerations of the legal and policy environments in which sex workers operate, and actions to address the important role of stigma, discrimination, social isolation, and violence targeting sex workers is needed. Criminalized work environments continue to undermine HIV prevention strategies, and pose serious barriers to utilization of SRH services among sex workers globally $[9,11,14,23,31,66]$. Policy shifts away from criminalization, towards a human rights-based model for sex workers, remain critically needed, during armed conflict and in the fragile peace that follows. As significant barriers in access to care appear to be for sex workers in post-conflict settings, local level multilevel strategies which address factors at different levels, including individual risk factors, partner-level, social determinant, etc., may be most successful to address the severe structural barriers impeding sex workers' health and human rights in these settings.

Future public health interventions in conflict and post-conflict settings should seek to promote peer-led programmes and initiatives on the ground, in addition to recognizing sex workers as key stakeholders/experts in high-level policy consultations. In Kenya and Uganda, UNHCR and implementing partners have worked closely with sex workers in the development of programmes, based on sustainable and improved comprehensive services including HIV and reproductive health, community social services and livelihood interventions [67]. Both cases provided evidence that much can be achieved within a six-month period: sex worker-led organizations and community outreach can be established, confidential and respectful healthcare services can be provided, and protection systems strengthened. These examples illustrate how the active engagement and involvement of sex workers is not only possible, but can also lead to 
improved quality of HIV prevention measures [3]. Future public health interventions should additionally seek to target other vulnerable groups, including refugees and migrants broadly, men who have sex with men, transgender individuals, and the partners and clients of sex workers (e.g. military, peacekeepers, and police) in conflict and post-conflict environments. In Cambodia, for example, a brand of condoms marketed specifically to the military since 1997 has helped reduce rates of unprotected sex between Cambodian soldiers and sex workers, from $70 \%$ to $54 \%$ [33]. Clients have an important supportive role to play in supporting sex worker programmes, which should not be understated. If left out, they may undermine efforts to reduce safety concerns, sexual exploitation, and gender based violence. Community-led activities should be strengthened within the community which promote responsibility not only among sex workers, but also their partners [67]. Lastly, while the importance of better linking HIV and SRH services in the general population and for sex workers has been previously discussed, demonstrated to be feasible, and linked to improved health outcomes in a number of settings (e.g., linked to increased condom use, HIV testing, and lowering HIV and STI rates) [45, 68], special efforts to develop and implement 'best practices' for such service integration within the unique challenges faced by conflict-affected settings are required.

\section{Limitations and directions for future research}

Since too few studies exist in this area to have employed a systematic review or meta-analysis, we employed a comprehensive review methodology to meet our objectives. Challenges arose in distinguishing the fluid boundaries between acute conflict and post-conflict states, and conflations of sex work with transactional sex (i.e., exchange of non-monetary commodities with noncommercial partners) or human trafficking for the purposes of sexual exploitation. While many studies defined transactional sex as the exchange of sex for both monetary and non-monetary commodities, when they focused specifically on non-monetary exchanges with noncommercial partners they were excluded from this review. Most studies did not explicitly articulate the ways in which working and living in conflict and post/conflict settings may impact risk of HIV/STIs and access to SRH services for sex workers, creating large gaps in our understanding of distinct pathways in these contexts. Given that very few studies employed longitudinal designs, studies incorporating temporal aspects that would more easily allow inferences regarding the impacts of conflict on sex workers' health and access to care, such as studies that compare pre and post-conflict conditions and health outcomes, may be particularly useful. In addition, many people who exchange sex to supplement their incomes in humanitarian and post-conflict settings do not self-identify as sex workers, making research and surveillance in this area a challenge. To the best of our knowledge, this review is the first synthesis of evidence addressing social and structural drivers of HIV/STIs and SRH among conflict-affected sex workers.

\section{Conclusions}

Results from this review demonstrate the presence of numerous social and structural factors increasing HIV/STI risks, and creating severe barriers in access to HIV and SRH services for conflict-affected sex workers. Significant gaps in context specific sex worker-focused research, policy, and programming were identified. While recommendations are available to guide interventions with sex workers in conflict and post-conflict settings, universal, national, regional, and local policies and regulations are largely absent, and the degree to which sex workers are accessing SRH services during emergencies remains unclear. A paradigm shift from the behavioural and biomedical approach to HIV among sex workers, to a health and human rights approach, in displacement and postconflict settings is strongly recommended.

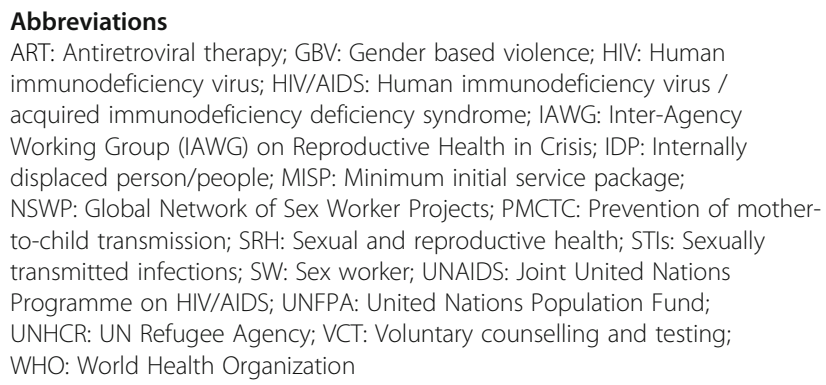
immunodeficiency virus; HIV/AIDS: Human immunodeficiency virus / acquired immunodeficiency deficiency syndrome; IAWG: Inter-Agency Working Group (IAWG) on Reproductive Health in Crisis; IDP: Internally displaced person/people; MISP: Minimum initial service package; NSWP: Global Network of Sex Worker Projects; PMCTC: Prevention of motherto-child transmission; SRH: Sexual and reproductive health; STIs: Sexually transmitted infections; SW: Sex worker; UNAIDS: Joint United Nations Programme on HIV/AIDS; UNFPA: United Nations Population Fund; UNHCR: UN Refugee Agency; VCT: Voluntary counselling and testing; WHO: World Health Organization

\section{Acknowledgments}

AF was supported in her placement by a Canadian Institutes for Health Research Award. SG is supported by the Canadian Institutes of Health Research, and the National Institute of Health. KS is supported by a Canada Research Chair in Global Sexual Health and HIV/AIDS and Michael Smith Foundation for Health Research.

\section{Funding}

Not applicable.

\section{Availability of data and materials \\ Not applicable.}

\section{Authors' contributions}

AF led the searching, screening, and analysis of records and drafted the article. Together with SG and KS, she was involved in the design of the review and early conception of the project. KS and SG conceived of the study, were involved in the design of the project, provided direction on conduct of the review, resolved decisions about inclusion criteria, were closely involved in intermediate draft revisions, and approved the final paper. JB provided conceptual insight and feedback on revisions, and approved of the final paper. 


\section{Authors' information}

Alyssa Ferguson, BA, MPH, is a graduate of the Master of Public Health in Global Health program from the University of Alberta's School of Public Health. Her research interests focus on social and structural determinants of sexual and reproductive health for marginalized women, particularly in subSaharan Africa. This review was carried out as part of her MPH degree field practicum placement hosted and supervised by the Gender and Sexual Health Initiative, BC Centre for Excellence in HIV/AIDS.

Kate Shannon, BA, BSC, MPH, PhD, is Director of the Gender \& Sexual Health Initiative at the BC Centre for Excellence in HIV/AIDS and an Associate Professor of Medicine and Associate Faculty in the School of Population and Public Health at University of British Columbia. Her research focuses on sexual health, HIV, and social justice inequities among marginalized populations, including sex workers, migrant and refugee women, and women living with HIV.

Jennifer Butler, BA, PhD, is senior technical advisor on HIV and key populations at UNFPA and leads global United Nations responses to HIV and sex work, men who have sex with men and transgender people, and support responses on HIV and people who use drugs and removing punitive laws, policies and practices.

Shira Goldenberg, BA, MSc, PhD, is a Research Scientist with the Gender \& Sexual Health Initiative of the BC Centre for Excellence in HIV/AIDS and an Assistant Professor in the Faculty of Health Sciences at Simon Fraser University. Dr. Goldenberg's research largely focuses on the unique health, safety and human rights issues faced by migrant and refugee/internally displaced sex workers and women living with HIV in Guatemala, Mexico, Uganda, and Canada.

\section{Ethics approval and consent to participate} Not applicable.

\section{Consent for publication}

Not applicable.

\section{Competing interests}

None to declare.

\section{Publisher's Note}

Springer Nature remains neutral with regard to jurisdictional claims in published maps and institutional affiliations.

\section{Author details}

${ }^{1}$ Gender and Sexual Health Initiative, British Columbia Centre for Excellence in HIV/AIDS, St. Paul's Hospital, 608-1081 Burrard Street, Vancouver, BC V6Z 1Y6, Canada. ${ }^{2}$ Department of Medicine, University of British Columbia, St. Paul's Hospital, 608-1081 Burrard Street, Vancouver, BC V6Z 1Y6, Canada. ${ }^{3}$ United Nations Population Fund (UNFPA), Eastern Europe and Central Asia Region (EECAR), Istanbul, Turkey. ${ }^{4}$ Faculty of Health Sciences, Simon Fraser University, Blusson Hall, 8888 University Drive, Burnaby V5A 1S6, Canada. ${ }^{5}$ Faculty of Health Sciences, Simon Fraser University, Gender and Sexual Health Initiative, BC Centre for Excellence in HIV/AIDS, St. Paul's Hospital, 608-1081 Burrard St, Vancouver, BC V6Z 1Y6, Canada.

\section{Received: 7 September 2016 Accepted: 4 October 2017}

\section{Published online: 04 December 2017}

\section{References}

1. Koffmar L. Global conflicts on the rise. Uppsala University Media News. 2015 [cited 2015 July 30]. Available from: http://www.uu.se/en/media/news/ article/?id=4906\&typ=artikel.

2. Becker J, Theodosis C, Kulkarni RHIV. AIDS, conflict and security in Africa: rethinking relationships. J Int AIDS Soc. 2008;11(3)

3. Burton A, Butler J, Marwah P, Mazzacurati C, Schilperoord M, Steen R. Addressing HIV and sex work. Forced Migration Review. 2010;Supplement.

4. Chi P, Bulage $P$, Urdal $H$, Sundby J. Perceptions of the effects of armed conflict on maternal and reproductive health services and outcomes in Burundi and northern Uganda: a qualitative study. BMC International Health and Human Rights. 2015;15(1)

5. Hankins C, Friedman SR, Zafard T, Strathdee S. Transmission and prevention of HIV and sexually transmitted infections in war settings: implications for current and future armed conflicts. AIDS. 2002;16:2245-52.

6. United Nations. Refugees - the numbers. 2016.
7. $\quad$ Spiegel PB. HIV/AIDS among conflict-affected and displaced populations: dispelling myths and taking action. Disasters. 2004;28:322-39.

8. Mock N, Duale S, Brown LF, Mathys E, O'Maonaigh HC, Abul-Husn NK. Conflict and HIV: a framework for risk assessment to prevent HIV in conflictaffected settings in Africa. Emerging Themes in Epidemiology. 2004;1(6)

9. Shannon K, Strathdee SA, Goldenberg SM, Duff P, Mwangi P, Rusakova M, Reza-Paul S, Lau J, Deering K, Pickles MR, Boily MC. Global epidemiology of HIV among female sex workers: influence of structural determinants. Lancet. 2015;382(9962):55-71.

10. Mills $E$, Singh $S$, Nelson BD, Nachega JB. The impact of conflict on HIV/AIDS in sub-Saharan Africa. Int J STD AIDS. 2006;17(11):713-7.

11. Goldenberg S, Muzaaya G, Akello M, Birungi J, Shannon K. War-related abduction and history of incarceration linked to high burden of HIV among female sex workers in conflict-affected Gulu. Northern Uganda. JAIDS Journal of Acquired Immune Deficiency Syndromes. 2016;73(1):109-16.

12. Inter-Agency Task Team on HIV and Young People. HIV Interventions for Young People in Humanitarian Emergencies. n.d.

13. Jewkes R. Comprehensive response to rape needed in conflict settings. Lancet. 2007;369(9580):2140-1.

14. Muldoon K, Akello M, Muzaaya G, Simo A, Shoveller J, Shannon K. Policing the epidemic: high burden of workplace violence among female sex workers in conflict-affected northern Uganda. Global Public Health. 2017;12(1):84-97.

15. Salama P, Dondero TJ. HIV surveillance in complex emergencies. AIDS. 2011; 15:S4-S12.

16. UNAIDS Inter-agency task team on gender and HIV/AIDS. HIV/AIDS, Gender and Conflict Situations. 2001

17. Westerhaus M. Linking anthropological analysis and epidemiological evidence: formulating a narrative of HIV transmission in Acholiland of northern Uganda. Journal of Social Aspects of HIV/AIDS. 2007:4(2):590-605.

18. Betsi N, Koudou BG, Cissé G, Tschannen AB, Pignol AM, Ouattara Y, Utzinger J. Effect of an armed conflict on human resources and health systems in Côte d'Ivoire: prevention of and care for people with HIV/ AIDS. AIDS Care: Psychological and Socio-medical Aspects of AIDS/HIV 2006;18(4):356-65

19. Casey SE, Chynoweth SK, Cornier N, Gallagher MC, Wheeler EE. Progress and gaps in reproductive health services in three humanitarian settings: mixedmethods case studies. Confl Heal. 2015;9(Suppl 1 Taking Stock of Reproductive Health in Humanitarian):S3.

20. Dhana A, Luchters S, Moore L, Lafort Y, Roy A, Scorgie F, et al. Systematic review of facility-based sexual and reproductive health services for female sex workers in Africa. Glob Health. 2014 Jun 10;10:46.

21. Shannon K, Kaida A, Rachlis B, Lloyd-Smith E, Gray G, Strathdee SA. Reconsidering the impact of conflict on HIV infection among women in the era of antiretroviral treatment scale-up in sub-Saharan Africa: a gender lens. AIDS. 2008 Sep 12;22(14):1705-7.

22. Baral S, Beyrer C, Muessig K, Poteat T, Wirtz AL, Decker MR, Sherman SG. Kerrigan D. Burden of HIV among female sex workers in low-income and middle-income countries: a systematic review and meta-analysis. 12. 2012;7:538-49.

23. Nyanzi S. Homosexuality, sex work, and HIV/AIDS in displacement and postconflict settings: the case of refugees in Uganda. International Peacekeeping. 2013 Aug;20(4):450-68

24. Baral SD, Friedman MR, Geibel S, et al. Male sex workers: practices, contexts, and vulnerabilities for HIV acquisition and transmission. Lancet. 2015;385(9964):260-273.

25. Poteat T, Wirtz AL, Radix A, et al. HIV risk and preventive interventions in transgender women sex worker. Lancet. 2015;385(9964):274-286.

26. Scorgie F, Chersich MF, Ntaganira I, Gerbase A, Lule F, Lo YR. Sociodemographic characteristics and behavioral risk factors of female sex workers in sub-saharan Africa: a systematic review. AIDS Behav. 2012;16(4):920-33.

27. Shahmanesh M, Patel V, Mabey D, Cowan F. Effectiveness of interventions for the prevention of HIV and other sexually transmitted infections in female sex workers in resource poor setting: a systematic review. Trop Med Int Health. 2008;13:659-79.

28. Decker MR, Crago AL, Chu SK, Sherman SG, Seshu MS, Buthelezi K, et al. Human rights violations against sex workers: burden and effect on HIV. Lancet. 2015;385(9963):186-99.

29. Tambiah Y. Sexuality and women's rights in armed conflict in Sri Lanka. Reproductive Health Matters. 2004 May;12(23):78-87.

30. Singh S, Mills E, Honeyman S, Suvedi BK, Pant NP. HIV in Nepal: is the violent conflict Fuelling the epidemic? PLoS Med. 2005;2(8):705-9.

31. Erickson M, Goldenberg SM, Ajok M, Muldoon KA, Muzaaya G, Shannon K. Structural determinants of dual contraceptive use among female sex workers in Gulu, northern Uganda. International Journal of Gynecology and Obstetrics. 2015;131(1):91-5. 
32. Alemayehu M, Yohannes G, Damte A, Fantahun A, Gebrekirstos K, Tsegay R, Goldberger A, Yebyo H. Prevalence and predictors of sexual violence among commercial sex workers in Northern Ethiopia. Reproductive Health. 2015;12(1):47.

33. Joint United Nations Programme on HIV/AIDS (UNAIDS). AIDS and conflict: a growing problem worldwide (Report on the global AIDS epidemic). 2004.

34. Fourie $P$, Schonteich M. Africa's new security threat. African Security Review. 2001;10(4):29-42.

35. International Office of Migration (IOM). Somali HIV Hotspot Mapping: Exploring HIV Vulnerability Among Populations at Increased Risk of Infection. 2008.

36. Larsen M, Sartie MT, Musa T, Casey SE, Tommy J, Saldinger M. Changes in HIV/AIDS/STI knowledge, attitudes and practices among commercial sex workers and military forces in Port Loko, Sierra Leone. (special issue: reproductive health and conflict). Disasters. 2004;28(3):239-54.

37. Maclin B, Kelly J, Kabanga J, VanRooyen M. They have embraced a different behaviour': transactional sex and family dynamics in eastern Congo's conflict. Culture Health \& Sexuality. 2015 Jan;17(1):119-31.

38. Muhwezi W, Kinyanda E, Mungherera M, Onyango P, Ngabirano E, Muron J, Kagugube J, Kajungu R. Vulnerability to high risk sexual behaviour (HRSB) following exposure to war trauma as seen in post-conflict communities in eastern Uganda: a qualitative study. Confl Heal. 2011;5(22)

39. Rehn E, Sirleaf EJ. Chapter 4: HIV/AIDS, women and war. Progress of the World's Women. 2002:47.

40. The Southern African Migration Project and the International Organization for Migration. HIVAIDS, population mobility and migration in southern Africa. 2005.

41. Tripodi P, Patel P. HIV/AIDS, peacekeeping and conflict crises in Africa. Medicine, Conflict and Survival. 2004;20(3):195-208.

42. Abdullah HJ, Ibrahim AF, King J. Women's voices, work and bodily integrity in pre-conflict, conflict and post-conflict reconstruction processes in Sierra Leone. IDS Bulletin. 2010;41:37-45.

43. Dupas $P$, Robinson J. The (hidden) costs of political instability: evidence from Kenya's 2007 election crisis. J Dev Econ. 2012 Nov;99(2):314-29.

44. Ntumbanzondo M, Dubrow R, Niccolai LM, Mwandagalirwa K, Merson MH. Unprotected intercourse for extra money among commercial sex workers in Kinshasa, Democratic Republic of Congo. AIDS Care: Psychological and Socio-medical Aspects of AIDS/HIV. 2007;18(7):777-85.

45. Harrison K, Claass J, Spiegel PB, Bamuturaki J, Patterson N, Muyonga M, Tatwebwa LHIV. Behavioural surveillance among refugees and surrounding host communities in Uganda, 2006. Ajar-African. Journal of Aids Research. 2009 Apr;8(1):29-41.

46. Laurent C, Henzel D, Mulanga-Kabeya C, Maertens G, Larouze B, Delaporte E. Seroepidemiological survey of hepatitis $C$ virus among commercial sex workers and pregnant women in Kinshasa, Democratic Republic of Congo. Int J Epidemiol. 2001;30(4):872-7.

47. Gazi R, Mercer A, Wansom T, Kabir H, Saha NC, Azim T. An assessment of vulnerability to HIV infection of boatmen in Teknaf, Bangladesh. Conflict and Health. 2008;2(1):5

48. International Office of Migration (IOM). Urgent Scale-up Needed for HIV Prevention and Treatment in Somalia. 2012.

49. Rowley E, Spiegel, PB, Tunze, Z, Mbaruku, G, Schilperoord, M, Njogu, P. Differences in HIV-related behaviors at Lugufu refugee camp and surrounding host villages, Tanzania. Conflict and Health. 2008;2(1):13.

50. Bing E, Ortiz DJ, Ovalle-Bahamon RE, Cheung KC, Huang FH, Ernesto F, Duan NH. HIV/AIDS behavioral surveillance among Angolan military men. AIDS Behav. 2008;12(4):578-84

51. Scorgie F, Vasey K, Harper E, Richter M, Nare P, Maseko S. Human rights abuses and collective resilience among sex workers in four African countries: a qualitative study. Global Health. 2013;9(1):33.

52. Global Commission on HIV and the Law. HIV and the law: risks, rights and health. New York: UNDP HIV/AIDS Group; 2012.

53. Todd C, Nasir A, Stanekzai MR, Scott PT, Close NC, Botros BA, Strathdee SA, Tjaden J. HIV awareness and condom use among female sex workers in Afghanistan: implications for intervention. AIDS Care: Psychological and Socio-medical Aspects of AIDS/HIV. 2011;23(3):348-56.

54. Kriitmaa K, Testaa A, Osmanb M, Bozicevicc I, Riednerd G, Malungue J, Irving G, Abdalla I. HIV prevalence and characteristics of sex work among female sex workers in Hargeisa, Somalia. AIDS. 2010;24(Supplement 2):S61-S7.
55. Inter-agency Working Group (IAWG) on Reproductive Health in Crises Inter-agency field manual on reproductive health in humanitarian settings. 2010

56. Krause SK, Jones RK, Purdin SJ. Programmatic responses to refugees' reproductive health needs. Int Fam Plan Perspect. 2000;26(4):181-7.

57. World Health Organization. Prevention and Treatment of HIV and other Sexually Transmitted Infections for Sex Workers in Low- and Middle-income Countries: Recommendations for a public health approach. 2012.

58. Kerrigan D, Kennedy C, Morgan-Thomas R, Reza-Paul S, Mwangi P, Win KT, McFall A, Fonner VA, Butler J. A community empowerment approach to the HIV response among sex workers: effectiveness, challenges, and considerations for implementation and scale-up. Lancet. 2015;385(9963):172-185.

59. Alarya M, Lowndes CM, Van de Perre P, Behanzin L, Batona G, Guedoua FA, Konateh I, Traore I, Asamoah-Adu C, Akinochok E, Nagot N. Scale-up of combination prevention and antiretroviral therapy for female sex workers in West Africa: time for action. AIDS. 2013;27(9):1369-1374.

60. Goldenberg S, Strathdee SA, Perez-Rosales MD, Sued O. Mobility and HIV in Central America and Mexico: a critical review. Journal of Immigration and Minority Health. 2012;14(1):48-64.

61. Dreser A, Caballero M, Leyva R, Cuadra SM, Kageyama ML, Bronfman M. Mobility, sex workers and HIV/AIDS: the vulnerability of migrant sex workers in Central America and Mexico. Abstract no. E11624. International Conference on AIDS. 2002.

62. International Planned Parenthood Federation. Countries where sex work ('prostitution') is deemed illegal. [Internet]. 2014 [cited August 21, 2015] from http://www.hivandthelaw.com/countries-where-sex-work-prostitutiondeemed-illegal.

63. Beyrer C, Crago AL, Bekker LG, Butler J, Shannon K, Kerrigan D, Strathdee SA An action agenda for HIV and sex workers. Lancet. 2015;385(9964):17-23.

64. Scorgie F, Nakato D, Harper E, Richter M, Maseko S, Nare P, Smit J, Chersich M. We are despised in the hospitals': sex workers' Experiences of accessing health care in four African countries. Culture Health \& Sexuality. 2013;15(4):450-465.

65. Mtetwa S, Busza J, Chidiya S, Mungofa S, Cowan F. "You are wasting our drugs": health service barriers to HIV treatment for sex workers in Zimbabwe. BMC Public Health. 2013;13(698):1471-2458.

66. Shannon K, Goldenberg SM, Deering KN, Strathdee SA. HIV infection among female sex workers in concentrated and high prevalence epidemics: why a structural determinants framework is needed. Current opinion in HIV/AIDS. 2014;9(00).

67. United Nations High Commissioner for Refugees (UNHCR). HIV and sex work in refugee situations: A practical guide to launching interventions an issue affecting women, men, girls, Boys and communities. 2010.

68. Kennedy C, Spaulding AB, Brickley DB, Almers L, Mirjahangir J, Packel L, Kennedy GE, Mbizvo M, Collins L, Osborne K. Linking sexual and reproductive health and HIV interventions: a systematic review. I Int AIDS Soc. 2010;13(26)

\section{Submit your next manuscript to BioMed Central and we will help you at every step:}

- We accept pre-submission inquiries

- Our selector tool helps you to find the most relevant journal

- We provide round the clock customer support

- Convenient online submission

- Thorough peer review

- Inclusion in PubMed and all major indexing services

- Maximum visibility for your research

Submit your manuscript at www.biomedcentral.com/submit
) Biomed Central 